\title{
Optimization of energy spending with accelerated ventilation
}

\author{
Pustovaya Olessia ${ }^{1, *}$, and Pustovoy Evgeniy ${ }^{1}$ \\ ${ }^{1}$ Federal State Budget Educational Institution of Higher Education “Far Eastern State Agrarian University”, Russia
}

\begin{abstract}
Currently the cost of electric power to maintain indoor microclimate of a production facility is one of the highest. This issue is especially acute for livestock farming, where chambers and placements are not sealed from outside temperature and other factors. One of the most difficult issues of energy systems efficiency improvement is the development of adaptive climate controls for production areas and placements. A large number of factors, some of which are caused by the influence of random variables, makes the development of an algorithm for controlling ventilation systems a multi-faceted task. Classical methods of calculating microclimate parameters and their management do not allow to effectively use the adaptive control capabilities of energy efficiency of the processes under consideration. In this case the ventilation systems operation requires an excessive consumption of electric power since their design is calculated according to the maximum temperature indicators of the facility under study. One way to optimize the operation could be the introduction of an automated control system using strict algorithm or fuzzy logic algorithm. In this case, the economization of power consumption can reach up to $50 \%$ per a ventilation unit output. The authors propose using a concept of wind-cold index as a basis for constructing adaptive control of an accelerated ventilation system. Its assessment was made for the fixed indoor air movement speed. The introduction of a wind-cold index concept allows using a coefficient of correction due to the combined influence of an air movement speed in the room and air temperature, which, in turn allows to increase the minimum adjustment temperature from 16 degrees Centigrade to 18 degrees Centigrade (0C) while maintaining comfortable conditions for animals. The introduction of correction coefficients allows reducing energy expenditure by $32 \%$ in accelerated ventilation system use, that is, by the 5 th month. The calculations made by authors show that to improve the adaptive control process, it is necessary to include air humidity into the algorithm as another parameter. To determine the impact of this parameter on the adaptive control process will be the goal of further research.
\end{abstract}

\section{Introduction}

Maintaining the microclimate at the production premises is one of the most difficult academic areas to analyze and research. A large number of interacting factors, such as humidity, temperature, environmental conditions, and others, significantly complicate the analysis. The most difficult in this regard are premises for keeping livestock, the productivity of which depends on the quality of maintaining the microclimate. This issue is particularly relevant to cattle-keeping facilities.

Recently, the tethered method of keeping livestock with periodic walking of farm animals on specialized sites has become more widespread. In summer, high indoor temperatures cause overheating which leads to livestock death. One solution to the problem is the use of high-speed ventilation which cools the surface of the animal's body. In this case, the air flow withdraws excess heat and discharge it to the external environment. According to calculations, the heat efflux when the temperature drops by $3-400 \mathrm{C}$ can reach up to $128 \mathrm{~kJ} / \mathrm{h}$. $[1-15]$

\footnotetext{
Corresponding author: pus14@rambler.ru
} 
cowshed is $6.5 \mathrm{~m}$ along the ridge (includes two identical rooms for 200 heads). In the premises of the first team, a hydro-wash system is installed for cleaning manure. The second team is located in a completely identical room of the cowshed with a scraper installation for manure cleaning.

The room has forced ventilation. During the period of study, high-speed ventilation based on VOK-6,3 fans (Fig. 1. a) was used. The number of installed fans in the room is 8 on each side. The air is supplied through windows, the doors at the ends of the room, and the ventilation shafts on the ridge of the roof. For comparison, the design and the structure of the second team room was identical to that of the working room of the first team. The room is equipped with $1.5 \mathrm{~kW}$ Multifan fans, the temperature control is not enabled, and the fan operation mode is round-the-clock.

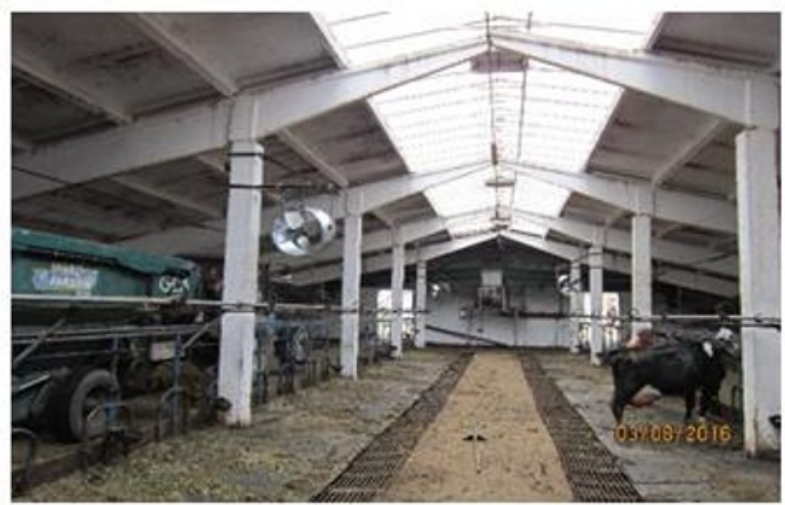

a.

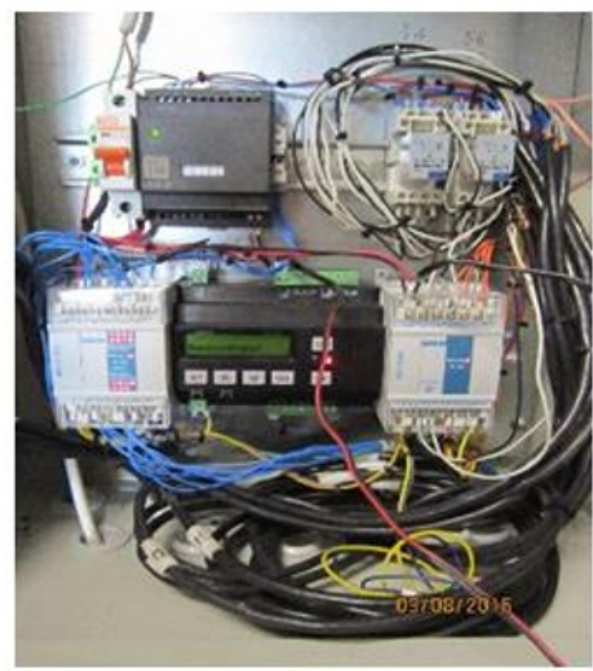

b.

Fig. 1. Cowshed premises (a. interior of a 400-head cowshed; b. automated control system based on PR200 manufactured by "Owen" company).

The fans were controlled by a PR200 microcontroller (Fig. 1. b), which has software that allows you to operate the fans in stages depending on the room temperature, starting from the temperature of $16^{\circ} \mathrm{C}$ in increments of $2^{\circ} \mathrm{C}$. The fans are started in pairs with output at full power at a temperature of $22^{\circ} \mathrm{C}$. The temperature registration for the automated system was carried out by 6 temperature sensors installed at key points of the room.

The study of the operation of the high-speed ventilation system involved the use of LOGGER100 loggers manufactured by the "Owen" company. Temperature and humidity were recorded in the cowshed. Such registration was performed every 30 minutes. The obtained data could be presented in a graphic form, or in the MS Excel format

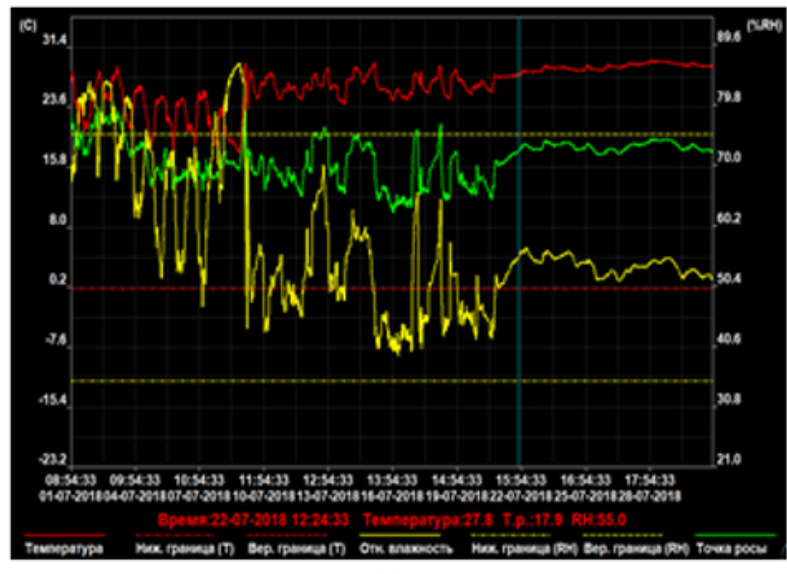

a

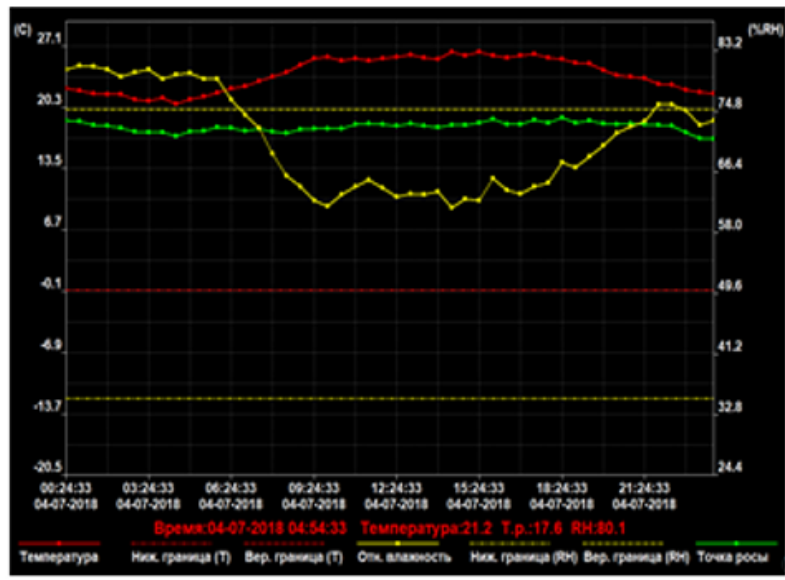

b.

Fig. 2. LOGGER 100 data (a. graph reflecting changes in temperature and humidity conditions within a month; b. graph reflecting changes in temperature and humidity conditions within a day).

\section{Research results}

Monitoring of microclimate parameters was carried out in the period from May to October in 2018 and 2019. An example of registered characteristics is given in Figure 2a. (data from the logger for July 2018). This figure shows the temperature, humidity, and dew point in the room of the first team for the period from July 1 to July 31,2018 . Figure $2 \mathrm{~b}$ reflects the diurnal variation of temperature and humidity for July 4, 2018.

The obtained graphs (Fig.3) allow us to estimate the power consumption of the ventilation unit during the day in different periods. If we consider the data for May 24, 
2018 (Fig. 3a.), the room temperature ranged from $14.5^{\circ} \mathrm{C}$ to $19^{\circ} \mathrm{C}$, humidity - from $63.5 \%$ to $67.8 \%$. Similar parameters for May 18, 2018 were as follows: humidity varied from $58.3 \%$ to $65.1 \%$, temperature from $18 \cdot 1^{\circ} \mathrm{C}$ to $24^{\circ} \mathrm{C}$ (Fig. 3b).

All considered parameters can be assessed for the entire observation period (Fig. 3). The registered sawtooth characteristic in the spring and autumn period is due to a decrease in the ambient temperature at night and, as a result, a delayed decrease in the temperature in the cowshed.

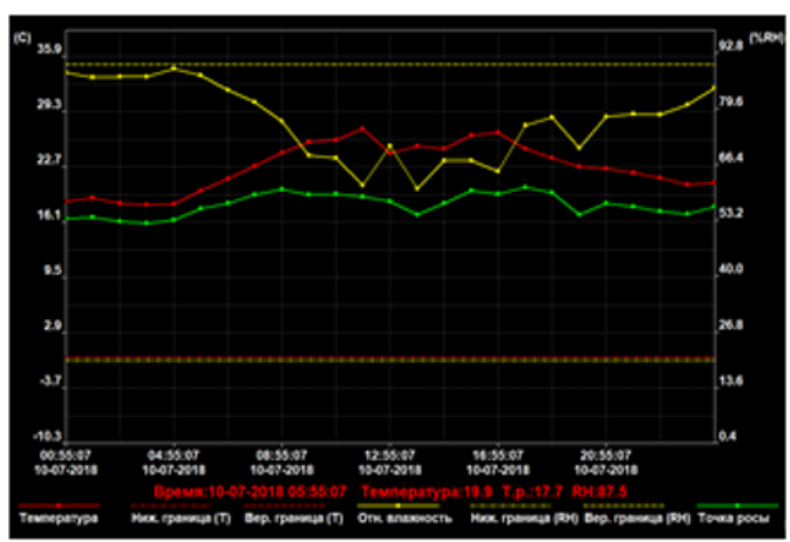

a.

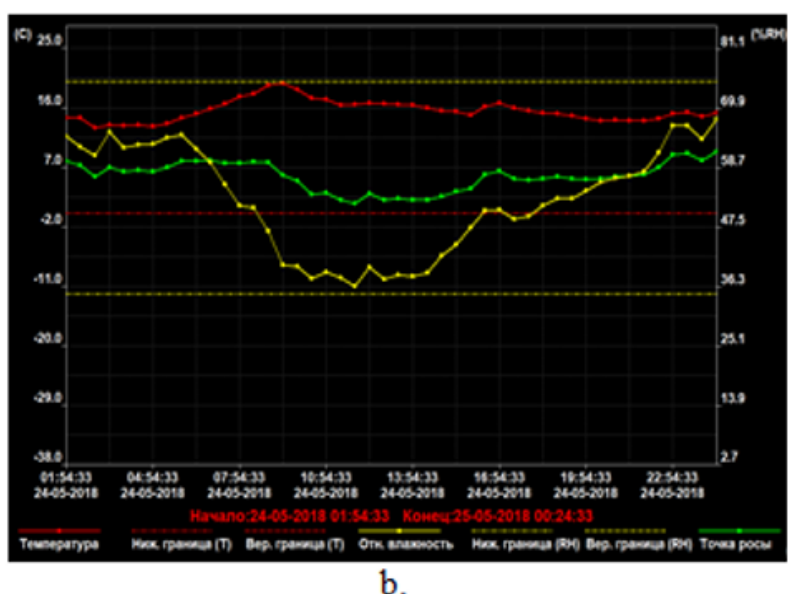

Fig. 3. LOGGER 100 data (a. graph of changes in temperature and humidity for May 24, 2018; b. graph of changes in temperature and humidity changes for May 18, 2018).

The most interesting mode of operation was noted in the spring and autumn period, where there are significant fluctuations in the studied parameters, which affected the amount of power consumed by the ventilation unit greatly.

The analysis of the obtained experimental data conducted for one day (May 18, 2018) showed that the power consumption (Table 1) significantly depends on climate conditions.

For this reason, in the spring and autumn period, the difference between daytime and night temperatures allows farms to reduce daily power consumption as shown by the analysis of the graph in Figure $3 b$ to 149.3 $\mathrm{kW}$, while without automation, power consumption would be about $288 \mathrm{~kW}$, which would reduce daily consumption by $138.7 \mathrm{~kW}$. At the same time, in the summer the difference between day and night temperatures is not so significant, so the power consumption for July 4, 2018 is $264 \mathrm{~kW}$

As shown by the results obtained (Fig. 4), the use of an automated control system for high-speed ventilation allows you to smooth out diurnal temperature fluctuations and reduce humidity in the room. In our case, the operation of the ventilation system with automatic temperature control (Fig.4b) allowed to stabilize humidity (from $52.2 \%$ to $57.2 \%$ ) and temperature (from $15.5^{\circ} \mathrm{C}$ to $27.9^{\circ} \mathrm{C}$ ) in the room, as well as to improve air exchange, which resulted in the increase of the feed intake and milk yield. In the room of the second team, humidity fluctuations ranged from $60.6 \%$ to $88.1 \%$ and the temperature varied from $16.5^{\circ} \mathrm{C}$ to $28.2^{\circ} \mathrm{C}$ (Fig. 4a.), the air in the room was more humid and warm, which creates discomfort.

Table 1. Calculation of the ventilation unit power consumption for May 18, 2018

\begin{tabular}{|c|c|c|c|c|c|}
\hline 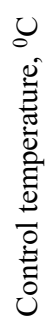 & 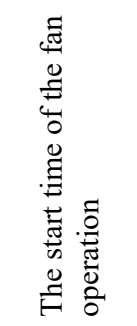 & 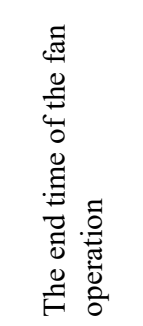 & 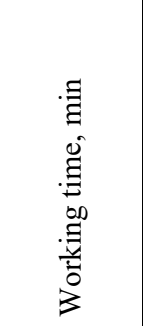 & 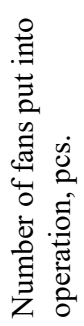 & 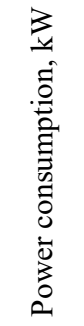 \\
\hline 16 & & & $24 \mathrm{y}$ & 4 & 36 \\
\hline 18 & $6 \mathrm{~h} 24 \mathrm{~m}$ & $24 \mathrm{~h} 00 \mathrm{~m}$ & $17 \mathrm{~h} 36 \mathrm{~m}$ & 4 & 52.4 \\
\hline 20 & $7 \mathrm{~h} 54 \mathrm{~m}$ & $19 \mathrm{~h} 24 \mathrm{~m}$ & $11 \mathrm{~h} 36 \mathrm{~m}$ & 4 & 34.4 \\
\hline \multirow[t]{2}{*}{22} & $8 \mathrm{~h} 24 \mathrm{~m}$ & $13 \mathrm{~h} 24 \mathrm{~m}$ & \multirow[t]{2}{*}{$8 \mathrm{~h} 54 \mathrm{~m}$} & \multirow[t]{2}{*}{4} & \multirow[t]{2}{*}{26.5} \\
\hline & $15 \mathrm{~h} 54 \mathrm{~m}$ & $17 \mathrm{~h} 54 \mathrm{~m}$ & & & \\
\hline \multicolumn{5}{|c|}{ Total } & 149.3 \\
\hline
\end{tabular}

The obtained experimental data characterize the energy consumption for the system with strict algorithm, programmed by software. However, modern automated systems have adaptive software, which makes quite relevant the study of the influence of small variables, such as changes in heat generated by animals while the external conditions change.

The heat released by animals or humans is most often considered as a design value that does not require clarification when planning the microclimate of production facilities. However, practical, and theoretical studies show that the amount of heat generated by animals is closely related to inside temperature, humidity, and air velocity. Currently, a comprehensive assessment of these values for industrial facilities is not performed, however, to improve the accuracy of automated systems will require taking into account possible changes in the amount of heat generated by animals under the complex influence of factors mentioned above. 
To assess the feasibility of using these parameters as a tool to increase the energy efficiency of automated control of accelerated ventilation, the authors evaluated air movement speed in a cow house. Based on the performed studies, the air flow rate ranges from 12.2 to 3.6 meters per second while the ventilation is on. To calculate possible influence of the considered complex of factors, the authors evaluated the wind-cold index in the facility under consideration. Since the cowsheds are identical, the first team's facility was taken under study. The temperature values for the calculation were selected in accordance with the fixed values in the facility. The calculation of the wind-cold index is given in table 2 . The index's calculation is done according to the formula provided by U.S. National Weather Service

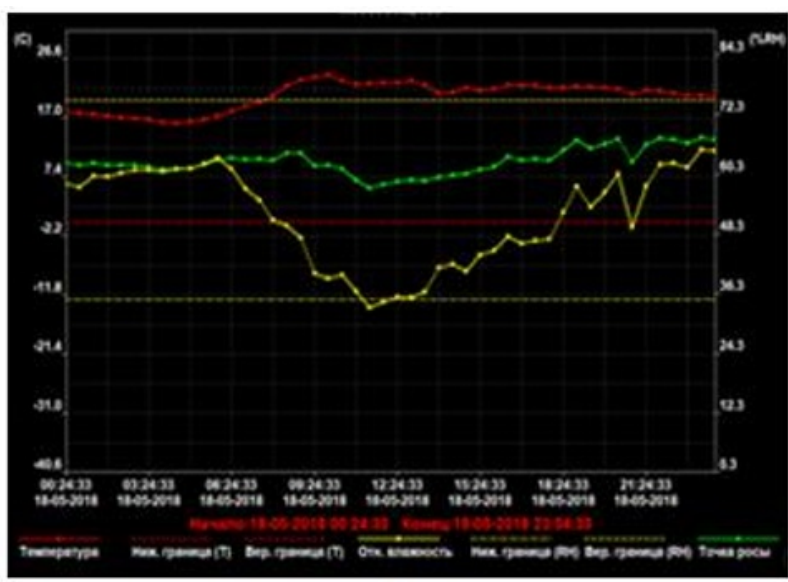

a.

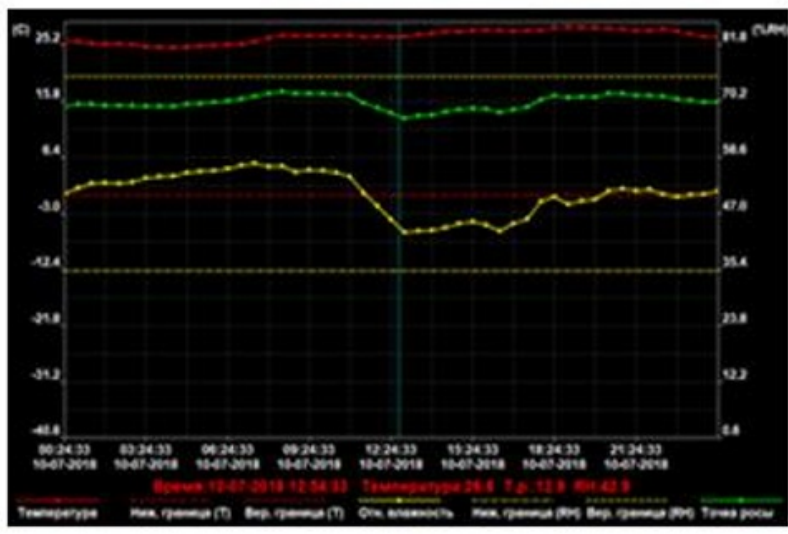

b.

Fig. 4. LOGGER 100 data (a. graph of changes in temperature and humidity conditions for July 10, 2018 (second team); b. graph of changes in temperature and humidity for July 10 , 2018 (first team)).
Table 2. Calculated values of the wind-cold index for the facility under study.

\begin{tabular}{|c|c|c|c|c|c|c|}
\hline$\#$ & $\begin{array}{c}\text { Inside temperature, } \\
\text { degrees Centigrade } \\
\left({ }^{\circ} \mathrm{C}\right)\end{array}$ & \multicolumn{5}{|c|}{$\begin{array}{c}\text { Air Velocity, meters per } \\
\text { second }(\mathrm{m} / \mathrm{s})\end{array}$} \\
\cline { 3 - 7 } & 16.0 & 12.2 & 11.9 & 10.2 & 6.8 & 3.6 \\
\hline 1 & 13.9 & 13.9 & 14.1 & 14.7 & 15.5 \\
\hline 2 & 16.5 & 14.5 & 14.6 & 14.8 & 15.3 & 16.1 \\
\hline 3 & 17,0 & 15,2 & 15,2 & 15,4 & 16,0 & 16,7 \\
\hline 4 & 17,5 & 15,9 & 15,9 & 16,1 & 16,6 & 17,3 \\
\hline 5 & 18,3 & 17,0 & 17,0 & 17,2 & 17,6 & 18,3 \\
\hline 6 & 18,7 & 17,5 & 17,5 & 17,7 & 18,1 & \\
\hline 7 & 18,9 & 17,8 & 17,8 & 18,0 & 18,4 & \\
\hline 8 & 19,1 & 18 & 18,1 & 18,2 & 18,7 & \\
\hline 9 & 19,5 & 18,6 & 18,6 & 18,8 & 19,2 & \\
\hline 10 & 20,0 & 19,2 & 19,3 & 19,4 & 19,8 & \\
\hline 11 & 20,5 & 19,9 & 19,9 & 20,1 & 20,5 & \\
\hline 12 & 21,0 & 20,6 & 20,6 & 20,9 & & \\
\hline 13 & 21,2 & 20,9 & 20,9 & 21,0 & & \\
\hline
\end{tabular}

As it is shown by the calculations (table \#2) the lower is the ambient temperature, the greater is its cooling capacity. Thus, at a temperature value of $16^{0} \mathrm{C}$, the felt temperature along with the air flow speed of 12.2 $\mathrm{m} / \mathrm{s}$ will amount to $13.9^{0} \mathrm{C}$, likewise with the air flow speed of $6.8 \mathrm{~m} / \mathrm{s}$, the felt temperature will amount to $14.7^{0} \mathrm{C}$. With increasing temperature, this difference decreases significantly and when a certain value is reached, a heat inflow to animal's body is observed instead of cooling. With options considered, the air flow rate for $6.8 \mathrm{~m} / \mathrm{s}$ is $21^{0} \mathrm{C}$, and at a speed of $3.6 \mathrm{~m} / \mathrm{s}$ it is $18.7^{0} \mathrm{C}$

The table above allows to make adaptive control corrections in the accelerated ventilation system management, based on the provisions that the air flow takes heat from body's surface, cooling it to a certain temperature. Basing on this notion, the reference point for the temperature setting in accelerated ventilation systems should be the temperature value to which the surface of animal's body is cooled rather than the inside air temperature in the facility. Therefore, taking this fact into account, the automatic control settings can be adjusted accordingly. Currently the system is configured to turn on / off the fans pairwise when the minimum value reaches $16^{\circ} \mathrm{C}$ and start upwards with the intervals of $2^{\circ} \mathrm{C}$ with the temperature reaching $22^{\circ} \mathrm{C}$, all fans are deployed.

The introduction of wind-cold index allows to shift the temperature control border for $16^{\circ} \mathrm{C}$ with an increment of $2^{\circ} \mathrm{C}$; for $18^{\circ} \mathrm{C}$ it's $1.5^{0} \mathrm{C}$; for $20^{\circ} \mathrm{C}-1.0^{\circ} \mathrm{C}$; for $22^{\circ} \mathrm{C}-0^{\circ} \mathrm{C}$, accordingly, which will reduce the ventilation system operating time to achieve the desired effect.

The analysis of power consumption was carried out for a ventilation system with strict control algorithm without considering the wind-cold index but taking into account its influence. The calculation of operating time for an accelerated ventilation system was done for the period from May to September according to the diagrams obtained with the help of loggers installed in the facility (Fig. 2, 3, 4). The total operating time of the ventilation system is shown in Figure 5. 


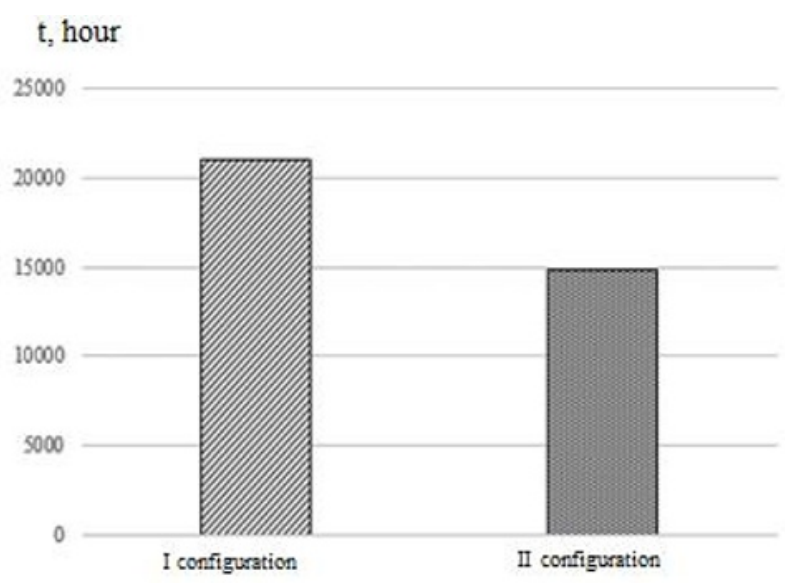

Fig. 5. The total operating time of the accelerated ventilation system (I configuration - without the wind-cold index; II configuration - with the wind-cold index).

The presented diagram illustrates that the number of operating hours of the accelerated ventilation system using the wind-cold index drops significantly with the difference of about $30 \%$, which leads to substantial savings of electric energy (Fig. 6).

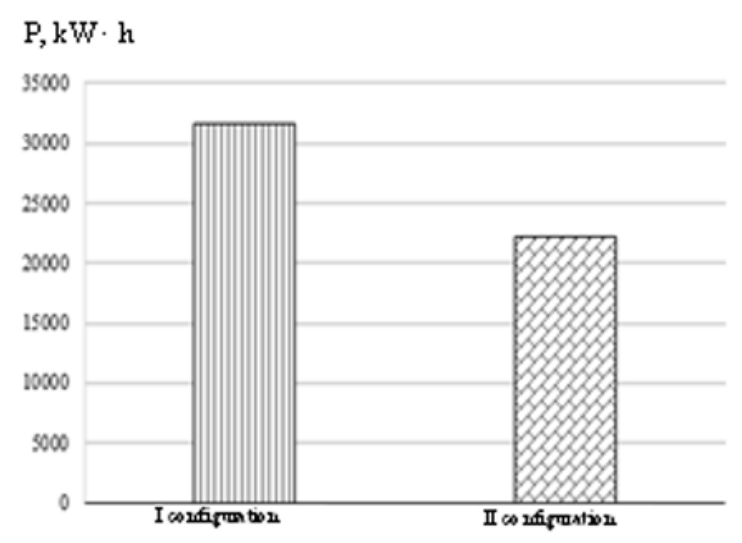

Fig. 6. Electric energy consumption (I configuration - without the wind-cold index; II configuration - with the wind-cold index).

The difference between power consumption in the first and second configurations made up 30\%, which is significant for agricultural enterprises.

The efficiency of wind-cold index use in a livestock facility will vary essentially depending on external temperatures. Considering system efficiency during the season (Fig. 7), the total energy savings will amount $14,246 \mathrm{~kW} \cdot \mathrm{h}$, which is about $32 \%$, with the total energy consumption of $44064 \mathrm{~kW} \cdot \mathrm{h}$ by the ventilation system during the season.

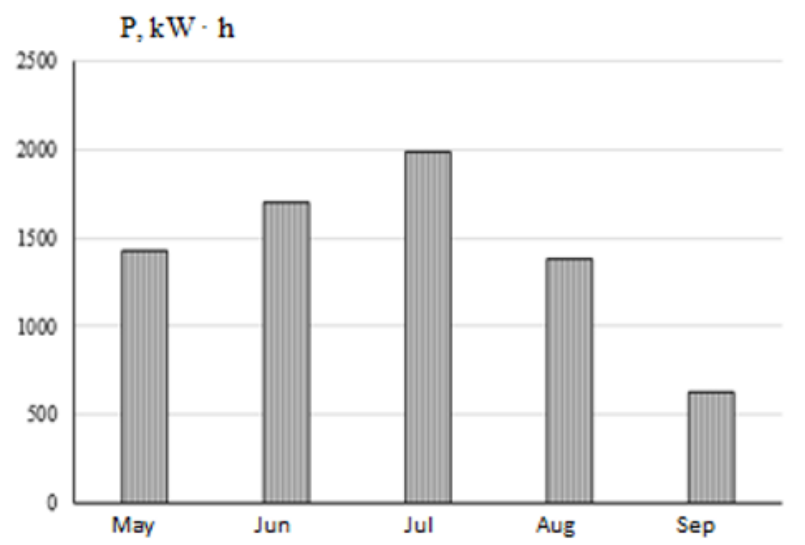

Fig. 7. The difference in power consumption between I and II configurations during the operation of the accelerated ventilation system (I configuration - without the wind-cold index; II configuration - with the wind-cold index).

Consequently, the use of regulation with the windcold index in adaptive control systems will lead to significant savings in electric energy consumption.

It should be noted however, that the considered factors require further investigation of the relationship between the wind-cold index and the effect of humidity on power consumption by the accelerated ventilation system.

\section{Conclusions}

The optimization of temperature and humidity modes in a cow house is one of the key indicators for improving the conditions of cattle maintenance. The results obtained during the research indicate that the use of automated control systems based on microcontrollers, PR200, manufactured by OWEN company in particular, allows to smooth out fluctuations of indoor temperature and humidity, as well as to reduce power consumption for maintaining the desired microclimate inside the facility. This way electric power savings can reach up to $50-52 \%$ during spring-autumn period, and up to $10-15 \%$ in summer.

The introduction of wind-cold index as one of microclimate characteristics will allow to move to the adaptive control of the microclimate parameters in industrial facilities. The analysis of inside temperature changes with the use of wind-cold index together with air flow speed showed that the automated control system can be reconfigured to higher temperatures without losing comfortable conditions for animals. For the facilities of the first and second teams, the introduction of correcting temperature coefficients allowed to reduce electric power consumption by $32 \%$.

The study assessment shows that it is necessary to introduce air humidity as an additional parameter into the algorithm to improve the adaptive control management. To determine the impact of this parameter on the adaptive management process will be the goal of further research.

The use of automated systems is based on a strict algorithm with exact parameters, however, the use of 
intelligent systems will allow to remove strict restrictions from process control and make the system work variable, that is, provide a further reduction in electric power consumption.

\section{References}

[1] V.F. Vtoriy, V.V. Gordeev, S.V. Vtoriy, E.O. Lantsova, Weather influence on temperature and humidity conditions in the cowshed, Bulletin of the All-Russian Research and Development, Design and Technology Institute of Livestock Breeding Mechanization 3, 23, 67-72 (2016)

[2] V.F. Vtoriy, V.V. Gordeev, S.V. Vtoriy, E.O. Lantsova, Assessment of the temperature and humidity regime in the cowshed using graphical information modeling, Bulletin of the All-Russian Research and Development, Design and Technology Institute of Livestock Breeding Mechanization 4, 24, 67-72 (2016)

[3] S.S. Trunov, Analysis of energy modes of the cowshed, Bulletin of the All-Russian Research and Development Institute of Electrification of Agriculture 4, 21, 68-72 (2015)

[4] S.A. Rastimeshin, S.S. Trunov, An energyefficient method of combating air overheating in the cowshed, Don Agricultural Science Bulletin 2, 34, 24-27 (2016)

[5] O.A. Pustovaya, E.A. Pustovoy, Calculations for the high-speed ventilation system, Rural Mechanization Expert, 1, 24-25 (2018)

[6] H.H.R. Zanetoni, I.F.F. Tinôco, M. Barbari, L. Conti, G. Rossi, F.C. Baêta1, M.O. Vilela, C.G.S. Teles Jr., R.R. Andrade, Alternative form to obtain the black globe temperature from environmental variables, Agronomy Research 17, 3, 900-906 (2019)

[7] Li. Rong, Mechanisms of natural ventilation in livestock buildings: Perspectives on past achievements and future challenges. Biosystems engineering 151 (2016). ISSN: 1537-5110. Online ISSN: $1537-5129$

[8] L. Rong, B. Bjerg, T. Bartzanas, G. Zhang, Review on mechanism of natural ventilation in livestock buildings past studies future challenges, Aarhus, Denmark (26.06.2016-29.06.2016)

[9] D. Tikhomirov, A.N. Vasilyev, D. Budnikov, A.A. Vasilyev, Energy-saving automated system for microclimate in agricultural premises with utilization of ventilation air, J. Mobile Communication, Computation and Information, 1-8 (2019)

[10] M.A.A. El-Rahman, M.S.El Shal, M.K.A. ElWahab, M.M.A. El-Aziz, Study on ventilation in enclosed poultry houses [Electronic resource], Zagazig J. Agric. Res. 43, 6A (2016). Available at: http:/www.journals.zu.edu.eg/ journalDisplay.aspx? Journalld $=1 \&$ queryType $=\mathrm{M}$ aster

[11] F. Rojano, P.-E. Bournet, M. Hassouna, P. Robin, M. Kacira, C.Y. Choi, Modelling the impact of air discharges caused by natural ventilation in a poultry house. Biosystems Engin. 180, 168-181 (April 2019)

[12] Y. Wang, W. Zheng, B. Li, Li Xuanyang, A new ventilation system to reduce temperature fluctuations in laying hen housing in continental climate Biosystems Engineering 181, 52-62 (May 2019)

[13] T. Nicoletta, V. Francesca, C. Giovanni, P. Simona, Development of a CFD Model to Simulate Natural Ventilation in a Semi-Open Free-Stall Barn for Dairy Cows, M. C., Buildings (2075-5309), DB Applied Science \& Technology Source 9, 8, 183-183, 1. DOI: 10.3390/buildings9080183 (August 2019)

[14] V. Ronja, W. Lutz, Z. Werner, J.H. Stefan, B. Johannes, N. Knut, P. Martin, A. Ivonne, A.Konrad, H.-P. Isabel, S. Martin, S. Günther, Biosystems Engineering 164, 85-97. DOI: 10.1016/j.biosystemseng.2017.09.013 (December 2017)

[15] N. Tomás, G. Jim, F. Richard, S. Da-Wen, Optimising the ventilation configuration of naturally ventilated livestock buildings for improved indoor environmental homogeneity Building and Environment 45, 4, 983-995. DOI: 10.1016/j.buildenv.2009.10.005 (2010)

[16] C. Mikovits, W. Zollitsch, S.J. Hörtenhuber, J. Baumgartner, K. Niebuhr, M. Piringer, I. Anders, K. Andre, I. Hennig-Pauka, M. Schönhart, G. Schauberger, Impacts of global warming on confined livestock systems for growing-fattening pigs: simulation of heat stress for 1981 to 2017 in Central Europe, Int J Biometeorol 63, 2, 221-230 (February 2019). PMID: 30671619. ISSN: 1432-1254 